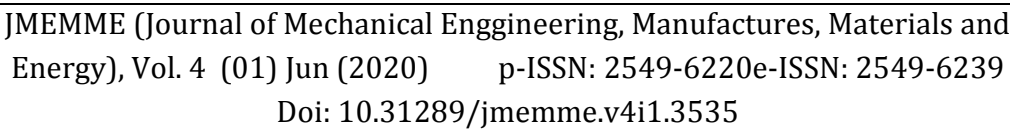

JMEMME (Journal of Mechanical Engineering, Manufactures, Materials and Energy)

\title{
Identifikasi Kerusakan Tutup Radiator Terhadap Suhu Engine Toyota Kijang 5K
}

\section{Identification of Radiator Cap Damage To Engine Temperature Toyota Kijang $5 K$}

\author{
Firman Gunawan, Wilarso* \\ Program Studi Teknik Mesin, Sekolah Tinggi Teknologi Muhammadiyah Cileungsi \\ Diterima: 02-01-2020 ; Disetujui: ; Diterbitkan: 30-06-2020 \\ *Corresponding author: wilarso@sttmcileungsi.ac.id
}

\begin{abstract}
Abstrak
Kekurangan air radiator pada sistem pendingin mobil Kijang $5 \mathrm{~K}$, berdampak pada menurunnya perfoma kendaraan. Kebocoran ini menyebabkan air pendingin pada radiator menjadi berkurang dan dapat memicu terjadinya temperatur sistem pendingin tinggi (overheating) pada mesin. Pembahasan pengaruh kerusakan tutup radiator terhadap suhu engine Toyota kijang $5 \mathrm{~K}$ adalah dapat membantu meningkatkan pemahaman pengguna kendaraan pada umumnya tentang sistem pendinginan, dapat merawat dan memperbaiki jika terjadi kerusakan. Tujuan dari penelitian ini untuk mengetahui akar penyebab suhu engine terhadap kerusakan tutup radiator. Uji tutup radiator dilakukan secara observasi pada mobil Toyota Kijang $5 \mathrm{~K}$ dengan menguji tekanan tutup radiator mengunakan alat ukur tes tekanan tutup radiator dan visualisasi terhadap komponen tutup radiator. Setelah dilakukan pemeriksaan terdapat kerusakan pada seal tutup radiator dan hasil uji tutup radiator $0,6 \mathrm{kgf} / \mathrm{cm} 2$ yang meyebabkan tekanan tutup radiator menjadi rendah, sedangkan tekanan standar nya $0.9 \mathrm{kgf} / \mathrm{cm} 2-1.03 \mathrm{kgf} / \mathrm{cm} 2 \mathrm{dan}$ terdapat kerusakan pada seal tutup radiator sehingga dapat menyebabkan engine overheating. Langkah perbaikan dengan mengganti komponen tutup radiator yang baru, Usaha yang perlu diperhatikan untuk mencegah terjadinya kerugian akibat kerusakan komponen sistem pendingin tersebut melakukan pengecekan level aiar radiator secara berkala dan pastikan semua dilakukan dengan baik dan benar.

Kata Kunci: Radiator, Tutup Radiator, Overheating
\end{abstract}

\begin{abstract}
Lack of radiator water in the $5 \mathrm{~K}$ Kijang car cooling system, has an impact on decreasing vehicle performance. This leakage causes the cooling water in the radiator to decrease and can trigger a high cooling system temperature (overheating) on the engine. Discussion of the effect of damage to the radiator cap on the engine temperature of the Toyota $5 \mathrm{~K}$ deer is able to help improve the understanding of vehicle users in general about the cooling system, can treat and repair if damage occurs. The purpose of this study was to determine the root cause of engine temperature against damage to the radiator cap. The radiator cap test was carried out by observation on a Toyota Kijang 5 K car by testing the radiator cap pressure using a measuring instrument for the radiator cap pressure test and visualization of the radiator cap components. After inspection there is damage to the radiator cap seal and the result of the radiator cap test $0.6 \mathrm{kgf} / \mathrm{cm} 2$ which causes the radiator cap pressure to be low, while the standard pressure is $0.9 \mathrm{kgf} / \mathrm{cm} 2-1.03 \mathrm{kgf} /$ $\mathrm{cm} 2$ and there is damage to the radiator cap seal so that it can cause engine overheating. Repair steps by replacing the new radiator cap components, effort that needs to be considered to prevent losses due to damage to the cooling system components to check the level of the radiator regularly and make sure everything is done properly and correctly.
\end{abstract}

Keywords: Radiator, Radiator Cap, Overheating 
Gunawan, F., Identifikasi Kerusakan Tutup Radiator Terhadap ...

How to Cite: Gunawan, F.., 2020, Identifikasi Kerusakan Tutup Radiator Terhadap Suhu Engine Toyota Kijang 5K, JMEMME (Journal of Mechanical Enggineering, Manufactures, Materials and Energy), 4(01): 24-30 


\section{PENDAHULUAN}

Performa mobil Kijang 5K menurun yang disebabkan oleh kekurangan air radiator, pada saat berkendara temperatur air radiator tinggi, sehingga kendaraan sering berhenti untuk mendinginkan temperatur engine. Air radiator berkurang banyak faktor penyebabnya. Kerusakan seal pada cap radiator, kerusakan hose/pipa saluran air, tube buntu, tali kipas putus, tali kipas kendor, klem kendor. Adapun daya dorong fan radiator juga berpengaruh terhadap kenaikan suhu air radiator [1], faktor ini disebabkan desain fan yang tidak sesuai peruntukkannya dan yang perlu diperhatikan dalam berkendara, kondisi putaran fan, kerusakan vee belt, atau desain fan yang tidak sesuai peruntukkannya. Sirkulasi air radiator yang berada didalam mesin berfungsi untuk menyerap panas yang dihasilkan dari sistem pembakaran [2] atau gesekan komponen yang bergerak, serta mendinginkan sistem pelumasan. Proses pembakaran menimbulkan temperatur yang tinggi, agar tidak menimbulkan terjadinya overheating. Sedangkan komponen engine yang berputar mendapatkan pelumasan dari oli, supaya komponen yang bergerak tidak mengalami kerusakan. Oli yang panas mengalir menuju ke oil cooler untuk proses pendinginan [3], dimana didalam oil cooler terdapat tube yang mengalir air pendingin untuk menyerap panas oli.

Gambar 1. Bagian-bagian sistem pendingin (1. Water Pump, 2. Oil Cooler, 3. Engine Blok, 4. Regulator, 5. Radiator, 6. Cap Radiator, 7, Hose/pipa radiator.
Sistem pendingin (cooling system) terdapat beberapa komponen yang berfungsi, 1) Pompa air (Water Pump) berfungsi untuk memindahkan air dari radiator menuju ke engine. 2) Pendingin minyak pelumas (Oil Cooler) berfungsi untuk mendingin oli engine. 3) Blok engine berfungsi sebagai dudukan komponen engine seperti liner, piston, crankshaft, connecting rod dan lain-lain, sistem sirkulasi air radiator didalam blok engine ini berfungsi untuk meredam ledakan saat terjadi proses pembakaran dan menyerap panas dari pergerakan komponen engine yang dibawa oleh oli [4]. 4) Regulator berfungsi sebagai pengatur sirkulasi air pendingin menuju radiator atau kembali lagi ke engine, regulator ini mempunyai batas temperatur agar sirkulasi air pendingin tidak terhambat. 5) Radiator berfungsi untuk menyerap panas air [4] pendingin untuk di dinginkan dengan cara air mengalir melalui tangki radiator bagian atas menuju tube dan panas air mengalir melalui sirip radiator dan kemudian air menuju tanki radiator bagian bawah. Fungsi dari cap radiator sebagai penutup menjaga temperatur air pendingin stabil [5] dan agar tidak mendidih ditemperatur 100 oC. Kemudian hose atau pipa berfungsi mengalirkan air radiator menuju engine dan kembali lagi ke radiator.

Komponen radiator, dari tutup radiator, tangki radiator bagian atas, core radiator, tube radiator, tangki radiator bagian bawah, selang/pipa radiator, klem selang/pipa radiator, dari beberapa komponen radiator yang akan dijadikan penelitian terhadap kekurangan air radiator adalah tutup radiator. 
Tutup radiator ini berfungsi untuk menjaga atau mengontrol tekanan air dalam sistem pendingin mobil, sistem pendingin atau cooling system [6]. Kerusakan tutup radiator (cap radiator) dapat diketahui dengan dilakukan pengujian radiator cup tester dengan tekanan standar $0.9 \mathrm{kgf} / \mathrm{cm} 2$ - 1.03 $\mathrm{kgf} / \mathrm{cm} 2$

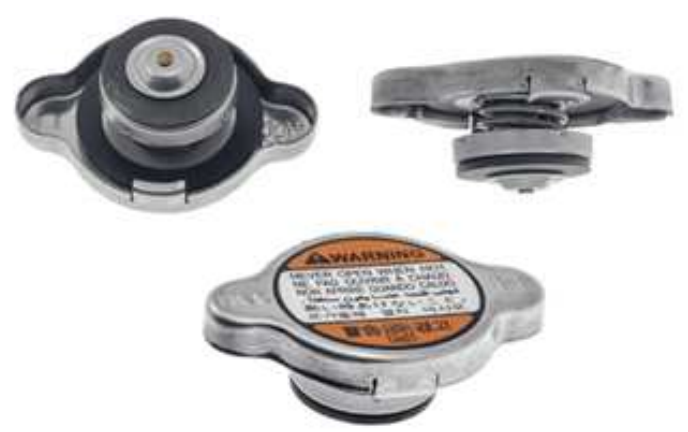

Gambar 2. Cap radiator

Tujuan penelitian ini untuk mengetahui akar penyebab terhadap kerusakan tutup radiator terhadap suhu engine pada mobil kijang, agar meminimalkan kerusakan mesin mobil kijang.

\section{METODE}

Dalam pengujian tutup radiator ini menggunakan alur penelitian pada gambar 1.

Waktu dan Tempat Penelitian:

1. Waktu Pelaksanaan

Penelitian ini mulai dilaksanakan pada bulan Januari 2020 .

2. Tempat penelitian

Tempat penelitian dilakukan di bengkel otomotif SMK PRATAMA, Alamat Jalan Raya Karanggan RT 02/03 Desa Karanggan Muda Kecamatan Gunung Putri Kabupaten Bogor.

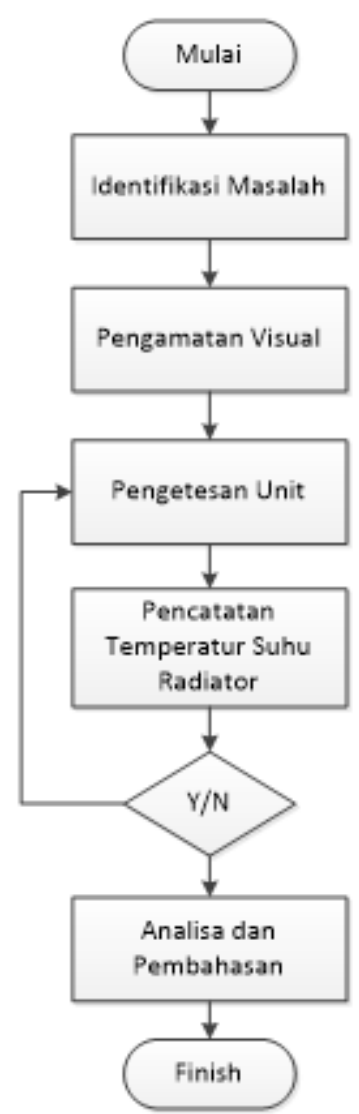

Gambar 1. Alur penelitian.

Alat dan Bahan

1. Alat

Peralatan yang digunakan dalam proses identifikasi kerusakan tutup radiator terhadap suhu engine antara lain :

- Radiator Cup Tester.

Untuk penguji kebocoran pada radiator [7] dalam kondisi mesin beroperasi atau kondisi tidak beroperasi dengan waktu tertentu, jika terjadi kebocoran ada terbaca pada alat cup tester dan tekanan akan cenderung menurun. Perubahan material untuk meminimalisasi kebocoran air pada sistem pendingin, juga akan berdampak pada kerusakan komponen selang, cap, tube [8]. 


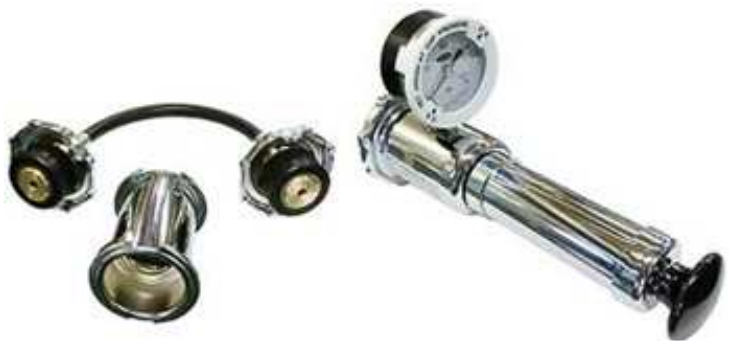

Gambar 3. Radiator Cup Tester

2. Bahan.

Bahan yang digunakan dalam proses identifikasi kerusakan tutup radiator terhadap suhu engine radiator mobil kijang $5 \mathrm{~K}$.

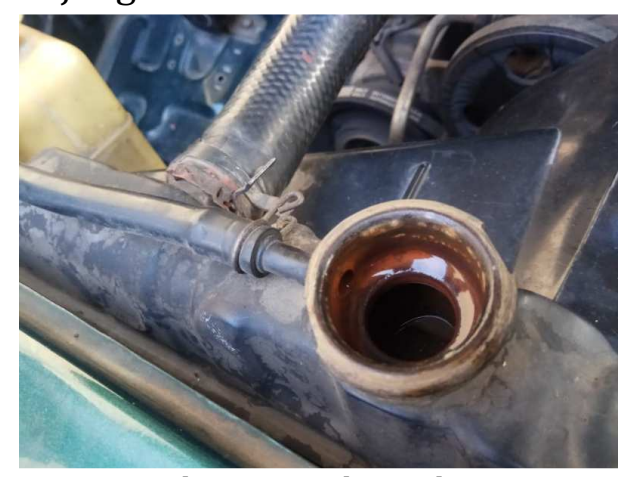

Gambar 4. Kondisi radiator

Prosedur penelitian pengujian tutup radiator:

1. Tutup radiator dibuka menggunakan tangan (dilarang membuka menggunakan alat bantu).

2. Lakukan pemeriksaan seal yang berada di bagian dalam tutup radiator dan periksa kelenturan dibagian dalam maupun luar.

3. Periksa pegas pada tutup radiator, dengan cara ditekan, apakah pegas kembali normal, jika tidak kerusakan bisa disebabkan oleh pegas..

4. Pemeriksaan tutup radiator dengan tester.

5. Pemasangan tutup radiator sesuai bentuk dan ukuran.

6. Kemudian pemasangan pompa tester, pada dudukan tutup radiator.
7. Setelah selesai pemasangan, pompa menggunakan alat tester. Dan periksa tekanan pada tutup radiator, serta perhatikan tekanan tidak boleh kurang dari 0,6 kg/cm2.

8. Untuk menjaga alat kerja aman dan dapat dipergunakan kembali, selesai pekerjaan agar dibersihkan dan dikembalikan ketempatnya.

\section{HASIL DAN PEMBAHASAN}

Setelah dilakukan pengamatan dan pemeriksaan pada system pendingin mobil Toyota kijang $5 \mathrm{~K}$ yang menyebabkan overheating adalah:

1. Hasil pengukuran tekanan tutup radiator [9] 0,6 kgf/cm2

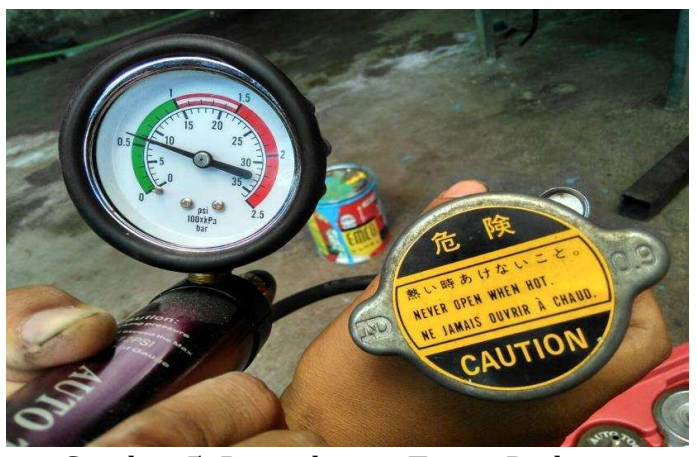

Gambar 5. Pengukuran Tutup Radiator

Data hasil penelitian setelah dilakukan penggantian tutup radiator.

Tabel 1. Pengujian setelah penggantian tutup radiator.

\begin{tabular}{llll}
\hline Waktu & \multicolumn{2}{l}{ Tekanan } & satuan \\
\hline 08.00 & 9 & psi & \\
08.05 & 8 & psi & \\
08.10 & 8 & psi & \\
08.15 & 8 & psi & \\
08.20 & 8 & psi & \\
08.25 & 8 & psi & \\
\hline
\end{tabular}

2. Seal pada tutup radiator ini berdampak pada kurangnya air pendingin, karena posisi penutupan 
Gunawan, F., Identifikasi Kerusakan Tutup Radiator Terhadap ...

yang tidak pas atau akan mengakibatkan air radiator akan saat engine bekerja dengan temperatur normal maupun abnormal [10], tekanan udara yang didalam radiator lebih tinggi, air radiator akan membentuk scaling yang bisa menghambat laju aliran air tube radiator [6].

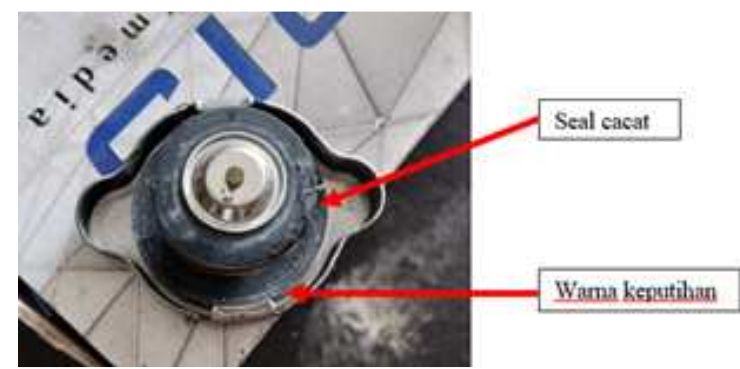

Gambar 6. Kerusakan Seal Tutup Radiator dan Warna Keputihan

Hasil pengamatan dan pemeriksaan terhadap tutup radiator yang berpengaruh terhadap meningkatnya suhu engine adalah ditemukan kerusakan seal tutup radiator dan tekanan tutup radiator yang sudah di bawah minimum ukuran standarisasi pabrikan. Pada tabel 2 menunjukkan hasil uji sebelum dilakukan perbaikan tutup radiator.

Tabel 2. Hasil pengujian sebelum dilakukan penggantian tutup radiator.

\begin{tabular}{llll}
\hline Waktu & \multicolumn{2}{l}{ Tekanan } & satuan \\
\hline 08.00 & 5 & psi & \\
08.05 & 2 & psi & \\
08.10 & 1 & psi & \\
08.15 & 0 & psi & \\
\hline
\end{tabular}

\section{KESIMPULAN}

Berdasarkan dari uji tekanan pada tutup radiator sebelum dilakukan penggantian, tekanan cepat menurun, dari tekanan 5 psi - 2 psi dalam waktu 5 menit. Dan setelah diganti dengan tutup radiator yang baru, tekanan tetap stabil di 8 psi. Dari hasil analisa penyebab tekanan menurun disebabkan oleh kerusakan tutup radiator.

\section{PENGHARGAAN}

\section{REFERENCES}

[1] J. Girardeau, P. Sebastian, and J. Girardeau, "Turbine Blade Cooling System Optimization To cite this version: Science Arts \& Métiers ( SAM )," 2014.

[2] A. Roberts, R. Brooks, and P. Shipway, "Internal combustion engine cold-start efficiency: A review of the problem, causes and potential solutions," Energy Convers. Manag., vol. 82, pp. 327350, 2014.

[3] K. Kenny, S. Augustine, P. E. Prakash, and A. G. Nair, "Perfomance Upgrading of Engine By Oil Cooling System," vol. 5, no. 5, pp. 57-62, 2018.

[4] M. N. F. Nas, "Radiator pressure cap," no. 3, pp. 735-740, 2000.

[5] R. Piccione and S. Bova, "Engine rapid shutdown: experimental investigation on the cooling system transient response," J. Eng. Gas Turbines Power, vol. 132, no. 7, 2010.

[6] P. Proses, E. Channel, A. Pressing, and T. Sifat, "Jurnal Rekayasa Material, Manufaktur dan Energi FT-UMSU Jurnal Rekayasa Material , Manufaktur dan Energi FT-UMSU," vol. 1, no. 1, pp. 30-38, 2018.

[7] D. Dabholkar, D. Shenvi, N. Anekar, and O. Joshi, "Design of Wet Leak 
Test Machine for Radiators: A Study," Int. J. Curr. Eng. Technol., vol. 4, no. 4, pp. 343-346, 2011.

[8] S. Palani, R. Irudhayaraj, R. Vigneshwaran, M. Selvam, and K. A. Harish, "Study of cooling system in I.C. engine improving performance with reduction of cost," Indian J. Sci. Technol., vol. 9, no. 1, 2016.

[9] D. Thombare, "An Overview of Radiator Performance Evaluation and Testing An Overview of Radiator Performance Evaluation and Testing," no. August, pp. 7-14, 2014.

[10] L. Nyanti et al., "Effects of water temperature, dissolved oxygen and total suspended solids on juvenile barbonymus schwanenfeldii (Bleeker, 1854) and Oreochromis Niloticus (Linnaeus, 1758)," AACL Bioflux, vol. 11, no. 2, pp. 394-406, 2018. 